\title{
O037. Should aircrafts never land? Headache attributed to aeroplane travel: a new series of 140 patients
}

\author{
Federico Mainardi ${ }^{1 *}$, Ferdinando Maggioni ${ }^{2}$, Carlo Lisotto ${ }^{3}$, Giorgio Zanchin ${ }^{2}$ \\ From Abstracts from the 1st Joint ANIRCEF-SISC Congress \\ Rome, Italy. 29-31 October 2015
}

\section{Background}

Following our previously published paper on 75 cases [1], a new form of headache, Headache attributed to aeroplane travel $(\mathrm{AH})$, has been recently codified in the ICHD-3beta classification [2].

\section{Materials and methods}

Since our publication, we continued to receive worldwide filled-in questionnaires.

\section{Results}

Up to now, 140 cases (males: 59\%) were studied. A strictly unilateral side was reported in $85 \%$ of patients; side-shift in different attacks was observed in $21 \%$. The pain site was mainly frontal-orbital $(n=110)$ or frontal-parietal $(n=9)$. The mean age at onset was 35.9 years (range 7-63). AH attacks occurred during landing (in nine patients also during take-off), lasted less than 30 minutes and remitted spontaneously. Its intensity was very severe or severe. Only in 16 cases the first attack occurred during the first flight. The attacks presented in more than $50 \%$ of flights in 38 patients; 24 reported its occurrence during every flight. AH negatively affected the propensity to air travel in more than $75 \%$ of the sufferers. Prophylactic use of NSAIDs prevented or effectively relieved the attacks in more than $50 \%$ of cases.

\section{Conclusions}

Considering the impact of $\mathrm{AH}$, passengers should be appropriately informed about the existence of this severe headache, on its benign nature and its potential prevention.

\footnotetext{
* Correspondence: fmainardi@iol.it

${ }^{1}$ Headache Centre, Neurological Division, SS Giovanni e Paolo Hospital, Venice, Itay

Full list of author information is available at the end of the article
}

These new data confirm the stereotyped features of this specific headache, in keeping with the ICHD criteria.

Written informed consent to publish was obtained from the patient(s).

\begin{abstract}
Authors' details
${ }^{1}$ Headache Centre, Neurological Division, SS Giovanni e Paolo Hospital, Venice, Itay. ${ }^{2}$ Headache Centre, Department of Neurosciences, Padua University, Padua, Italy. ${ }^{3}$ Headache Centre, S. Vito al Tagliamento Hospital, S. Vito al Tagliamento, Italy.
\end{abstract}

Published: 28 September 2015

\section{References}

1. Mainardi F, Lisotto C, Maggioni F, Zanchin G: Headache attributed to airplane travel ("Airplane headache"). Clinical profile based on a large case series. Cephalalgia 2012, 32(8):592-599.

2. Headache Classification Committee of the International Headache Society (IHS): The International Classification of Headache Disorders, 3rd edition (beta version). Cephalalgia 2013, 33(9):627-808.

doi:10.1186/1129-2377-16-S1-A166

Cite this article as: Mainardi et al:: 0037. Should aircrafts never land? Headache attributed to aeroplane travel: a new series of 140 patients. The Journal of Headache and Pain 2015 16(Suppl 1):A166.

Submit your manuscript to a SpringerOpen ${ }^{\bullet}$ journal and benefit from:

- Convenient online submission

- Rigorous peer review

- Immediate publication on acceptance

- Open access: articles freely available online

- High visibility within the field

- Retaining the copyright to your article

Submit your next manuscript at $>$ springeropen.com

\section{SpringerOpen ${ }^{\circ}$}

